\title{
HDAC inhibition decreases XIST expression on female IVP bovine blastocysts
}

\author{
Clara Slade Oliveira ${ }^{1,2}$, Naiara Zoccal Saraiva ${ }^{1}$, Maria Helena Coelho Cruz ${ }^{1}$, Bruna Mazeti ${ }^{1}$, \\ Leticia Zoccolaro Oliveira ${ }^{1}$, Flavia Lombardi Lopes ${ }^{1}$ and Joaquim Mansano Garcia ${ }^{1}$ \\ ${ }^{1}$ Departamento de Medicina Veterinária Preventiva e Reprodução Animal, Universidade Estadual Paulista, \\ Jaboticabal, Brazil and ${ }^{2}$ Embrapa Dairy Cattle Research Center, Juiz de Fora, Brazil
}

Correspondence should be addressed to C S Oliveira; Email: claraslade@gmail.com

\begin{abstract}
During initial development, both $\mathrm{X}$ chromosomes are active in females, and one of them must be silenced at the appropriate time in order to dosage compensate their gene expression levels to male counterparts. Silencing involves epigenetic mechanisms, including histone deacetylation. Major X chromosome inactivation $(\mathrm{XCI})$ in bovine occurs between hatching and implantation, although in vitro culture conditions might disrupt the silencing process, increasing or decreasing X-linked gene expression. In this study, we aimed to address the roles of histone deacetylase inhibition by trichostatin A (TSA) on female preimplantation development. We tested the hypothesis that by enhancing histone acetylation, TSA would increase the percentage of embryos achieving 16-cell stage, reducing percentage of embryos blocked at 8-cell stage, and interfere with XCI in IVF embryos. We noticed that after TSA treatment, acetylation levels in individual blastomeres of 8-16 cell embryos were increased twofold on treated embryos, and the same was detected for blastocysts. Changes among blastomere levels within the same embryo were diminished on TSA group, as low-acetylated blastomeres were no longer detected. The percentage of embryos that reached the 5th cleavage cycle $118 \mathrm{~h}$ after IVF, analyzed by Hoechst staining, remained unaltered after TSA treatment. Then, we assessed XIST and G6PD expression in individual female bovine blastocysts by quantitative real-time PCR. Even though G6PD expression remained unaltered after TSA exposure, XIST expression was eightfold decreased, and we also detected a major decrease in the percentage of blastocysts expressing detectable XIST levels after TSA treatment. Based on these results, we conclude that HDAC is involved on $\mathrm{XCI}$ process in bovine embryos, and its inhibition might delay $\mathrm{X}$ chromosome silencing and attenuate aberrant XIST expression described for IVF embryos.

Reproduction (2013) 145 9-17
\end{abstract}

\section{Introduction}

Despite their phenotypic similarities, male and female embryos present some major differences regarding their preimplantation development pattern. Male embryos develop faster (Avery et al. 1992) and reach the blastocyst stage more frequently (Xu et al. 1992), while female embryos are more sensitive to in vitro culture (IVC; Edwards et al. 2001). Female IVF bovine blastocysts display lower cell numbers and increased apoptosis rates than their male counterparts (Oliveira et al. 2010). Furthermore, the ratio of male:female blastocyst in some in vitro systems is lower than the expected 1:1 (Avery et al. 1992, Lonergan et al. 1999, Wrenzycki et al. 2002). Also, abnormalities such as increased body weight at birth (Fernandez-Gonzalez et al. 2004) are described in mice especially for female embryos produced in vitro.

One of the main molecular differences between male and female embryos during preimplantation development is the double expression levels of $X$-linked genes, as at the beginning of development, female embryos still present two active $X$ chromosomes. One of them must be inactivated at the appropriate time for further development, a phenomenon known as dosage compensation, which takes place in the inner cell mass at the blastocyst stage in mouse (reviewed by Augui et al. (2011)). At the onset of this process, one $\mathrm{X}$ chromosome is coated by the upregulated XIST transcript, followed by asynchronous replication timing, and finally chromatin modifications set the stable inactive and condensed chromatin state (reviewed by Augui et al. (2011)). In mouse, paternal X chromosome undergoes imprinted inactivation from cleavage stages, and reactivation occurs in cells of the inner cell mass, in which random X inactivation occurs (Mak et al. 2004, Okamoto et al. 2004). Recent studies suggest that silencing of $X$ chromosome might be initiated in the absent of XIST, but XIST RNA is required for imprinted $\mathrm{X}$ chromosome inactivation $(\mathrm{XCl})$ and stabilization of 
silencing (Kalantry et al. 2009). XIST dependence for XCI appears to be stronger at genes that had acquired dosage compensation for longer time during evolution.

In previous studies, we demonstrated that HDAC inhibition by trichostatin A (TSA) has distinct effects between male and female blastocysts and that the increased acetylation levels did not affect blastocyst rates or cell numbers (Oliveira et al. 2010). In this study, we aimed to further investigate the effects of HDAC inhibition on female development. It is known that HDAC plays a role in $\mathrm{XCl}$, promoting deacetylation of the coding regions of $X$-linked genes and of the upstream region of XIST (O'Neill et al. 1999). O'Neill et al. (1999) showed that in murine ES cells, TSA prevents $\mathrm{XCl}$, and the subsequent removal of the inhibitor leads to normal $\mathrm{XCI}$.

Gene expression profiles comparing male and female embryos suggest that in bovine, $\mathrm{XCl}$ occurs between days 7 and 14 (Bermejo-Alvarez et al. 2011). However, $\mathrm{XCl}$-related mechanisms can be initiated in vitro as early as at the 2-cell stage, when low XIST expression can be detected, even though late replication can only be detected at early blastocyst stage (De La Fuente et al. 1999). In addition, when the expression pattern of X-linked genes displayed by in vitro-produced (IVP) embryos is compared with their in vivo counterparts, higher levels of XIST expression are detected on IVP embryos (Wrenzycki et al. 2002, Nino-Soto et al. 2007). Those results suggest that mechanisms regulating $\mathrm{XCl}$ are affected by IVC.

Therefore, the objective of this study was to investigate the effects of TSA on acetylation levels of individual blastomeres of female IVP bovine embryos just after embryonic genome activation (8- to 16-cell stage) and in blastocysts, and their effects on cell cycle progression and expression of X-linked genes. We tested the hypothesis that TSA would increase histone acetylation levels, affecting XCI-related events during IVC.

\section{Results}

\section{Standardization of $X$-sorted semen for IVF experiments}

Even though flow cytometer sperm sorting is well established (Seidel et al. 1999, Hamano 2007), we validated in our system for IVP of blastocysts. Briefly, 53 blastocysts from two replicates produced using X-bearing spermatozoa from the same bull were sexed using conventional PCR, and we detected $98.10 \%$ of female embryos. Therefore, we concluded that straws from Lagoa da Serra (Sertaozinho, Brazil) were adequate for performing experiments with female embryos.

\section{TSA treatment did not affect blastocyst development rate of female embryos}

We detected similar developmental rates for female embryos treated with $5 \mathrm{nM}$ TSA and control $(n=113$ cleaved embryos, 55-58 per group, obtained in three replicates. Blastocyst development (number/rate): control, 24/43.64\% and TSA, 21/36.21\%). In previous studies, we standardized $5 \mathrm{nM}$ concentration as being the less harmful tested for bovine embryos, considering apoptosis, cell number, and blastocyst rates (Oliveira et al. 2010, 2011).

\section{TSA treatment did not affect cleavage progression of female embryos}

We evaluated cleavage progression on female TSA-treated embryos compared with control group. Five replicates and a total of 641 cleaved embryos $(n=307-334$ per group; Table 1) were considered. In both groups, we saw a higher percentage of embryos classified at the 2nd and 4th cleavage cycle, followed by a lower $(P<0.05)$ percentage distributed in the 3 rd cleavage cycle and the lowest $(P<0.05)$ percentage classified at the 5 th cycle.

Therefore, considering that in bovine embryonic genome activation (EGA) occurs at the transition from the 4 th to the 5 th cleavage cycle, in our system, $\sim 37 \%$ of embryos 118 h.p.i. are distributed in EGA cleavage cycle or after. No difference was detected between TSA and control groups, regarding distribution between cleavage cycles. In conclusion, TSA did not affect cleavage cycle progression of female bovine embryos ranging from 2 to 32 cells.

\section{TSA enhances levels of H3k9ac on blastomeres from female 9-16 cell embryos}

We assessed twelve 9-16 cell embryos ( $n=6$ per group), totaling 156 blastomeres ( $n=77-79$ per group) divided into two replicates.

Mean fluorescence values of TSA group blastomeres were 2.21 -fold higher $(P<0.05)$ than control group blastomeres (Fig. $1 \mathrm{I}$ and II).

Besides the higher average acetylation levels, we noticed that $\mathrm{H} 3 \mathrm{k} 9 \mathrm{ac}$ levels of individual blastomeres

Table 1 Distribution of control and TSA-treated embryos with respect to their cleavage cycles $48 \mathrm{~h}$ after TSA treatment. Data from five replicates and a total of 641 cleaved embryos ( $n=307-334$ per group) obtained $118 \mathrm{~h}$ after IVF.

\begin{tabular}{lcccc}
\hline Groups & $\begin{array}{c}\text { 2nd cycle } \\
(2-4 \text { cells; } n(\%))\end{array}$ & $\begin{array}{c}\text { 3rd cycle } \\
(5-8 \text { cells; } n(\%))\end{array}$ & $\begin{array}{c}\text { 4th cycle } \\
(9-16 \text { cells; } n(\%))\end{array}$ & $(17-32$ cells; $n(\%))$ \\
\hline Control & $120(35.92)^{\mathrm{a}}$ & $91(27.24)^{\mathrm{b}}$ & $99(29.64)^{\mathrm{a}, \mathrm{b}}$ & $24(7.15)^{\mathrm{c}}$ \\
TSA & $111(36.15)^{\mathrm{a}}$ & $82(26.71)^{\mathrm{b}}$ & $97(31.59)^{\mathrm{a}, \mathrm{b}}$ & $17(5.53)^{\mathrm{c}}$ \\
\hline
\end{tabular}

a,b,c Means with different letters between lines are not equal ( $\chi^{2}$ test, $\left.P<0.05\right)$. No difference was detected between columns $\left(\chi^{2}\right.$ test, $\left.P<0.05\right)$. 

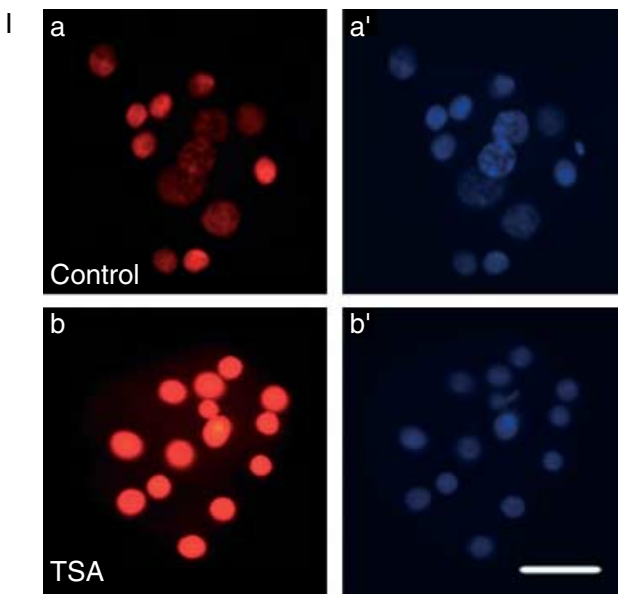

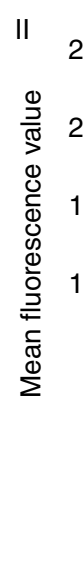

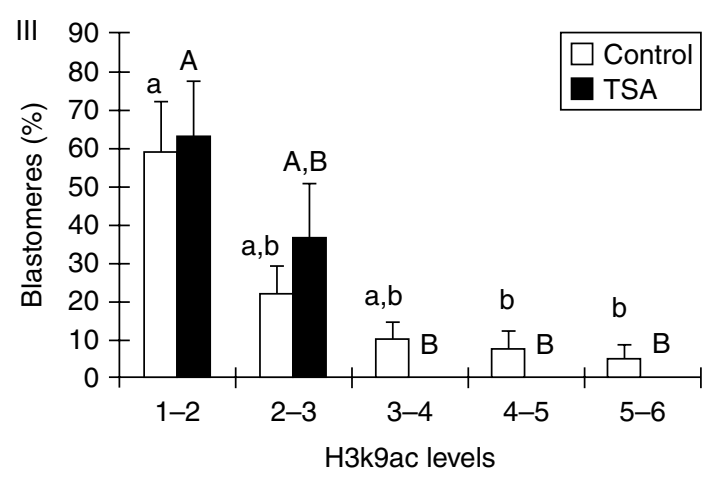

Figure 1 Levels of $\mathrm{H} 3 \mathrm{k}$ 9ac in blastomeres from 8- to 16-cell embryos treated with TSA. (I) Immunocytochemistry reaction for $\mathrm{H} 3 \mathrm{k} 9 \mathrm{ac}(\mathrm{Cy} 3$, red) in control (a) and treated (b) embryos. Nuclei were counterstained with Hoechst 33342 $\left(\mathrm{a}^{\prime}, \mathrm{b}^{\prime}\right)$. Bars indicate $50 \mu \mathrm{m}$. (II) Fluorescence intensity (mean \pm S.E.M.) in blastomeres from control and treated embryos. Asterisks indicates that means are not equal ( $t$-test, $P<0.05$ ). (III) Percentage (mean \pm S.E.M.) of blastomeres in $\mathrm{H} 3 \mathrm{k}$ 9ac level categories. In each embryo, blastomeres were normalized by the lower $\mathrm{H} 3 \mathrm{k} 9 \mathrm{ac}$ level. ${ }^{\mathrm{A}, \mathrm{B} / \mathrm{a}, \mathrm{b}}$ Means with different letters within the same group are not equal (Kruskal-Wallis and Dunn's multiple comparisons test, $P<0.05)$. Data from two replicates and 156 blastomeres ( $n=77-79$ per group) from embryos obtained $118 \mathrm{~h}$ after IVF. within the same embryo were similar within each TSA-treated embryo. On the other hand, for control group embryos, we found a high variation of $\mathrm{H} 3 \mathrm{k} 9 \mathrm{ac}$ levels among individual blastomeres. To analyze this difference, we normalized the blastomere acetylation levels on each embryo considering the lowest blastomere level. Therefore, we saw that in TSA-treated embryos, levels were ranging from 1 - to a maximum of 2.41-fold difference within blastomeres from the same embryo (Fig. 1III). On control group, a wider distribution was found, and levels of acetylation reached 5.92-fold higher.

On control group, we detected five classes of blastomeres (Fig. 1III), and the highest percentage of blastomeres $(59.24 \%)$ was classified in one- to twofold difference. Classes two- to threefold and three- to fourfold presented $22.22 \%$ and $10.35 \%$ of blastomeres respectively without displaying significant difference from none other class. Classes four- to fivefold and five- to sixfold showed similar percentages $(8.18 \%$ and $5.41 \%$ respectively), both of them lower $(P<0.05)$ than classes one- to twofold percentage. For TSA-treated embryos, only two classes of blastomeres were found (one- to twofold and two- to threefold), and no difference was detected among them $(63.26$ and $36.73 \%$ respectively). These results indicate that TSA increases blastomere levels and leads to a homogeneous distribution of
$\mathrm{H} 3 \mathrm{k} 9 \mathrm{ac}$ modification between blastomeres within each embryo, apparently by particularly increasing levels of low acetylated blastomeres.

\section{TSA increases levels of H3k9ac on both ICM and TE of female blastocysts}

Then, we analyzed levels of acetylation in female blastocysts developed into TSA-supplemented medium. We evaluated 12 blastocysts ( $n=5-7$ per group), separately for ICM and TE cells.

We saw that ICM and TE levels of acetylation were similar within groups (Fig. 2). TSA treatment increased $(P<0.05) \mathrm{ICM}$ and TE levels in the same manner.

Based on these results, we concluded that ICM and TE cells similarly responded to TSA treatment, by increasing their acetylation levels $\sim 2.35$-fold compared with control group.

\section{XIST expression was decreased in TSA-treated blastocysts}

Then we evaluated the effects of TSA on expression of $X$ chromosome genes XIST and G6PD. As we expected high variability of XIST expression among embryos, we decided to assess individual gene expression instead of embryo pool analysis, aiming not to mask distinct 

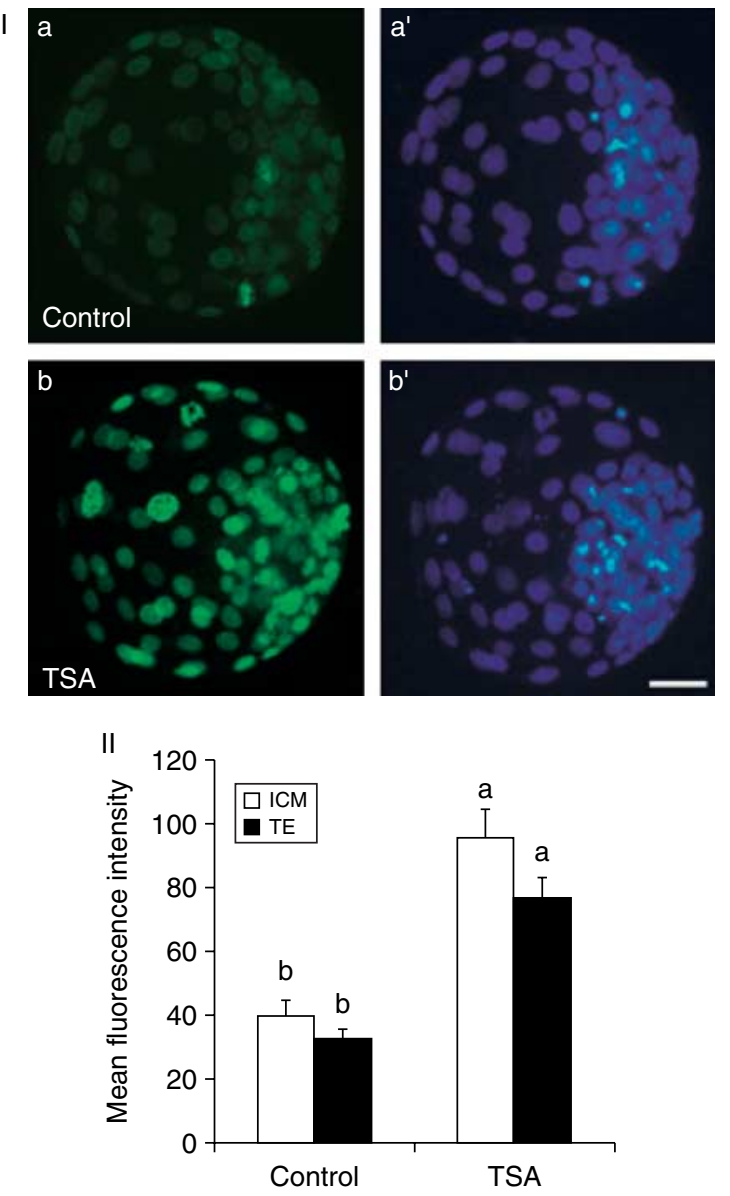

Figure 2 Levels of $\mathrm{H} 3 \mathrm{k} 9 \mathrm{ac}$ in bovine blastocysts treated with TSA. (I) Immunocytochemistry reaction for $\mathrm{H} 3 \mathrm{k} 9 \mathrm{ac}$ (Alexa 488, green) in control (a) and treated (b) embryos. Nuclei were counterstained with Hoechst $33342\left(a^{\prime}, b^{\prime}\right)$. Bars indicate $50 \mu \mathrm{m}$. (II) Fluorescence intensity (mean \pm s.E.M.) in inner cell mass and trophectoderm of control and treated blastocysts. ${ }^{\mathrm{a}, \mathrm{b}}$ Means with different letters are not equal (ANOVA one-way and Tukey's posttest, $P<0.05)$. Data from two replicates and 12 blastocysts ( $n=5-7$ per group) obtained 7 days after IVF.

profiles. We assessed 19 individual female blastocysts ( $n=9-10$ per group). We detected that preamplification efficiency of specific cDNA before gene expression analysis showed a high correlation $(r=0.9109)$ of cDNA quantity between samples and a high correlation $(P<0.05)$ between gene expression measurements (XIST, $r=0.9277$ and G6PD, $r=0.9107$ ) of samples before and after preamplification for the validated genes (Saraiva et al. 2012). Therefore, preamplification system was suitable for our experiments. Relative levels of G6PD mRNA remained unaltered between control and TSA-treated blastocysts (Fig. 3I). However, relative levels of XIST were 8.12-fold higher $(P<0.05)$ on control compared with TSA-treated blastocysts (Fig. 3II).

When we assessed relative levels of XIST for individual blastocysts (Fig. 3III and IV), we noticed that only one blastocyst $(10 \%)$ did not exhibit detectable XIST expression in control group, against $4(44.4 \%)$ in
TSA-treated group. Besides, levels of TSA-treated blastocysts that exhibited XIST expression were much lower than control group levels. Therefore, TSA treatment did not affect G6PD expression but decreased XIST expression in bovine blastocysts.

\section{Discussion}

This study provides data regarding the effect of TSA supplementation on female bovine preimplantation development. Our main findings are that I) TSA did not improve the percentage of embryos that reached 5th cell cycle, II) histone acetylation induced by TSA equalized blastomere levels, increasing especially levels of low acetylated cells, and III) HDAC inhibition decreased XIST expression in treated blastocysts, a fact that might delay $\mathrm{XCl}$ and consequently affect postimplantation development of those embryos.

$\mathrm{XCl}$ is an essential process of embryonic development that occurs in order to dosage compensate the expression of female genes to their male counterparts. In this process, $X I S T$ RNA is upregulated and coats one $X$ chromosome. $X I S T$ creates a transcriptionally silent nuclear compartment and induces gene repression by A-repeat-dependent mechanism (Chaumeil et al. 2006). XIST also appears to have a role in shaping the conformation of the inactive $X$ chromosome (Splinter et al. 2011).

In bovine, studies have shown that a percentage of IVP embryos present at least one blastomere exhibiting late replication during preimplantation development, at rates that varies from $28 \%$ in early blastocysts to $77 \%$ after hatching (De La Fuente et al. 1999). However, recent studies based on gene expression profile of male and female embryos suggest that dosage compensation occurs in bovine at some stage between hatching and implantation, which is inferred based on the presence of approximately a double amount of X-linked genes, including G6PD, at day 7, and the same amount at day 14 , comparing male and female counterparts (Bermejo-Alvarez et al. 2011).

It is known that IVC interferes with expression of $\mathrm{X}$-linked genes. Controversial results were found regarding G6PD expression, which was shown to be increased in some studies (Gutiérrez-Adán et al. 2000, Peippo et al. 2002, Wrenzycki et al. 2002, Lopes et al. 2007, Morton et al. 2007, Bermejo-Alvarez et al. 2011) and decreased in others (Merighe et al. 2009), when comparing female and male IVP blastocysts. Considering that G6PD varies its expression according to respiration and metabolism (Lopes et al. 2007), their different mRNA levels among systems might be related to stressful culture conditions. However, G6PD variations in the same system might regard to disruptions on the $\mathrm{XCl}$ process, as G6PD suffers dosage compensation after $\mathrm{XCl}$ in bovine (Basrur et al. 2004). Some authors describe $X$-linked expression in IVP blastocyst as aberrant, including higher levels of XIST expression (Wrenzycki et al. 2002, Nino-Soto 

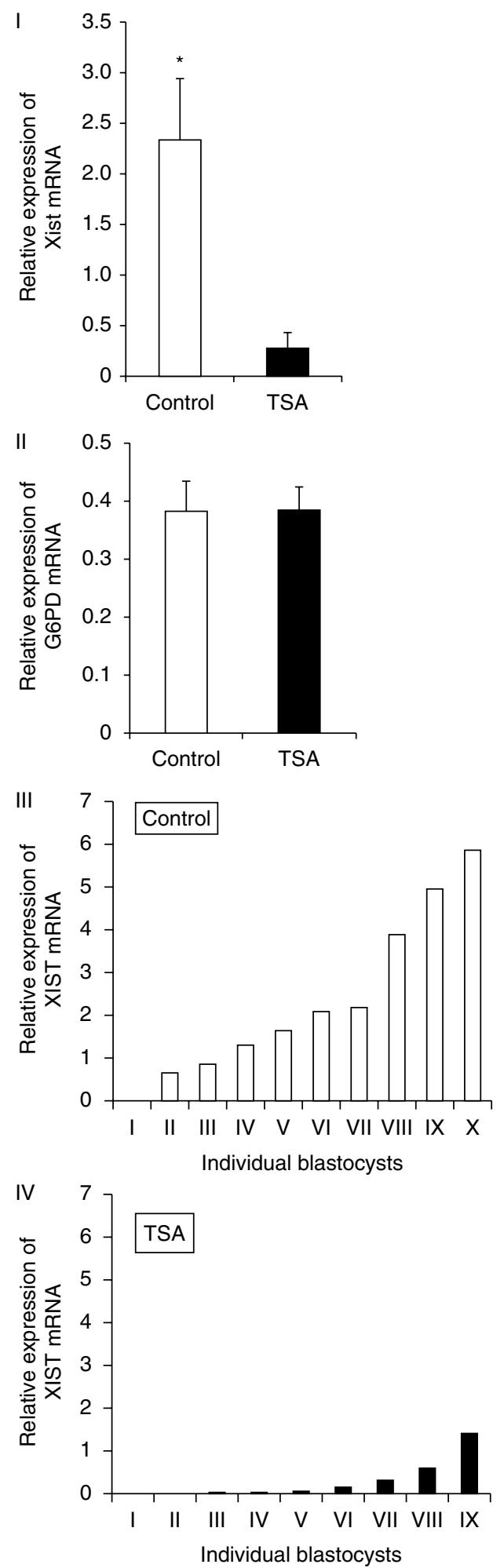

Figure 3 Relative expression levels of XIST (I, III, and IV) and G6PD (II) in female bovine blastocysts treated with TSA. (I and II) Bars indicate the mean value ( \pm S.E.M.) for individual embryos. Asterisks indicates significant difference with control group $(P<0.01$, Mann-Whitney $U$ test). (III and IV) XIST relative expression level for each blastocyst in control (III) and TSA (IV) groups. Data from 19 individual blastocysts $(n=9-10$ per group) obtained 7 days after IVF. et al. 2007). Our group found that only $23 \%$ of in vivo-produced blastocysts presented detectable XIST expression, against $80 \%$ of IVP blastocysts (Saraiva et al. 2012). Therefore, we think that as $\mathrm{XCl}$ is supposed to occur during the elongation phase, slower female development and loss of pregnancy could be related to a premature $\mathrm{XCl}$ caused by IVC conditions (personal observation). Here, we described that XIST expression was downregulated eightfold in TSA-treated embryos. This result agrees with the fact that deacetylation of coding regions of $\mathrm{X}$-related genes and of the upstream promoter of XIST is essential for $\mathrm{XCl}$, and HDAC inhibition prevents this and other XCl-related events, including XIST upregulation (O'Neill et al. 1999). In this case, TSA might have prevented deacetylation of XIST promoter and also its upregulation, which in control group was already occurring.

Recently, Matoba et al. (2011) described XIST inactivation by RNAi in reconstructed oocytes as an efficient strategy for improving development of female clones in mice. The authors argued that aberrant expression of XIST is one of the main disruptive mechanisms in nuclear reprogramming and suggest that the fate of cloned embryos is determined almost exclusively before implantation by their $\mathrm{XCl}$ status. Therefore, TSA supplementation might be an interesting approach aiming decreased XIST expression in clones, and this strategy might improve postimplantation development also for IVF embryos. Additionally, we detected that G6PD expression remained unaltered after HDAC inhibition. Although histone deacetylation has a fundamental role in regulating gene expression, HDAC inhibitors seem to directly affect transcription of only $2-10 \%$ of genes (Johnstone 2002). Therefore, TSA did not directly affect G6PD expression. Even though XIST coating initiates $\mathrm{XCl}$ process, $\mathrm{X}$-linked gene transcription does not seem to be coupled, as during reactivation of paternal $X$ in inner cell mass, cell transcription precedes loss of XIST coating in mice (Williams et al. 2011).

It might be the case that $\mathrm{XCl}$ was not achieved in control embryos neither in TSA-treated embryos, and the process at this developmental stage was only initiating. However, this certainly would have effects on implantation. XIST inhibition caused by TSA might retrieve their levels closer to in vivo-produced embryos. We think that this delay in the initiation of $\mathrm{XCl}$ process might be beneficial for IVP embryos and help their implantation and further development.

Apparently, TSA increased acetylation levels of 8-16 cell embryos especially on low acetylated blastomeres. In control group, we detected a remarkable difference between acetylation levels of blastomeres within the same embryo. This effect is not likely to be related to cell cycle, as increased $\mathrm{H} 3 \mathrm{k}$ ac levels can be observed both in interphase and in cells entering metaphase (Fig. 2). In treated group, blastomeres presented similar levels within the same embryo. Therefore, in TSA-treated 
embryos, levels of H3k9ac were equalized, and average levels increased 2.2-fold. As deacetylation of $X$ genes occurs at the onset of XCl process (O'Neill et al. 1999), those low acetylated blastomeres found in control group might be more susceptible to $\mathrm{XCI}$ and XIST upregulation.

Studies have revealed that TSA induces cell cycle arrest and apoptosis, by activating the expression of proapoptotic genes (Yakovlev et al. 2010) and by opening chromatin structure, which becomes more susceptible to endonucleases (Koyama et al. 2000). We have previously reported that $5 \mathrm{nM}$ TSA did not affect blastocyst cell number and apoptosis on female embryos (Oliveira et al. 2010). Here, we confirmed that TSA supplementation did not affect cleavage cycle progression of female blastocysts. However, in this concentration, no beneficial effect was observed on percentage of embryos blocked at 8-cell stage, as we hypothesized on previous studies.

In conclusion, our results show that HDAC inhibition using low TSA concentration has no effect over cleavage cycle progression and increases histone acetylation levels of female embryos, especially on low acetylated blastomeres. Based on our data, we conclude that XIST expression in bovine is related to HDAC and that HDAC inhibition decreases XIST mRNA levels. Whether or not decreased XIST expression levels are beneficial to postimplantation development remains to be elucidated.

\section{Materials and Methods}

\section{Supplements}

Reagents and culture media were purchased from Sigma Chemical Co. unless otherwise stated.

\section{Preparation and selection of oocytes}

Bovine ovaries from Bos Taurus $\times$ Bos Indicus crossbred were collected at a local slaughterhouse and processed within $2 \mathrm{~h}$ after killing. The ovaries were washed in saline $\left(37^{\circ} \mathrm{C}\right)$ and follicles measuring 3-8 $\mathrm{mm}$ in diameter were aspirated with an 18 -gauge needle coupled to a $20 \mathrm{ml}$ syringe. Cumulus-oocyte complexes (COCs) presenting at least three layers of cumulus cells and homogenous cytoplasm were selected under a stereomicroscope. The COCs were washed in HEPES-buffered TCM-199 (Gibco BRL) supplemented with 10\% fetal bovine serum (FBS; Cripion, Andradina, Brazil), $16 \mu \mathrm{g} / \mathrm{ml}$ sodium pyruvate, and $83.4 \mu \mathrm{g} / \mathrm{ml}$ amikacin (Instituto Biochimico, Rio de Janeiro, Brazil).

\section{In vitro maturation}

Groups of 15 COCs were transferred to $100 \mu \mathrm{l}$ drops of medium containing sodium bicarbonate-buffered TCM-199 supplemented with $10 \%$ FBS, $1.0 \mu \mathrm{g} / \mathrm{ml} \mathrm{FSH}$ (Folltropin, Bioniche Animal Health, Belleville, ON, Canada), $50 \mu \mathrm{g} / \mathrm{ml}$ human chorionic gonadotrophin (Profasi, Serono), $1.0 \mu \mathrm{g} / \mathrm{ml}$ estradiol, $16 \mu \mathrm{g} / \mathrm{ml}$ sodium pyruvate, and $83.4 \mu \mathrm{g} / \mathrm{ml}$ amikacin covered with sterile mineral oil (Dow Corning Co., Midland, MI, USA) and incubated for $24 \mathrm{~h}$ at $38.5^{\circ} \mathrm{C}$ in an atmosphere of $5 \% \mathrm{CO}_{2}$ in air under saturated humidity.

\section{IVF}

After in vitro maturation, the cumulus cells were partially removed from the oocytes by pipetting. Groups of 25 oocytes were washed twice and transferred to $30 \mu \mathrm{l}$ drops of TALP-IVF medium supplemented with $0.6 \% \mathrm{BSA}, 10 \mu \mathrm{g} / \mathrm{ml}$ heparin, $18 \mu \mathrm{M}$ penicillamine, $10 \mu \mathrm{M}$ hypotaurine, and $1.8 \mu \mathrm{M}$ epinephrine and covered with sterile mineral oil. Frozen straws of semen from the same bull sexed for X-chromosome bearing spermatozoa by flow cytometry (Lagoa da Serra, Sertãozinho, Brazil) were used. Flow cytometric sperm sorting based on differences in their DNA content is the best method for separation of $\mathrm{X}$ - and Y-chromosome bearing spermatozoa, and its accuracy is about 90\% (Seidel et al. 1999, Hamano 2007). Each straw containing $\sim 2$ million spermatozoa was centrifuged separately on a discontinuous $45 / 90$ Percoll gradient for $7 \mathrm{~min}$ at $3600 \mathrm{~g}$. The pellet was resuspended in $700 \mu \mathrm{l}$ TALP-IVF medium and again centrifuged for $5 \mathrm{~min}$ at $520 \mathrm{~g}$. After centrifugation, $80 \mu \mathrm{l}$ of the medium containing the pellet was collected from the bottom of the tube and homogenized in a conic tube. The final suspension was divided among five oocytecontaining drops, in a final concentration of $\sim 10^{4}$ spermatozoa for each oocyte. The plates were incubated at $38.5^{\circ} \mathrm{C}$ for $20 \mathrm{~h}$ in an atmosphere of $5 \% \mathrm{CO}_{2}$ in air under saturated humidity.

We also evaluated the sex of blastocysts produced with $\mathrm{X}$-bearing spermatozoa in our system by conventional PCR. Briefly, we selected two pairs of primers for $\mathrm{Y}$ chromosome (Primer 1, 5'-CCT CCC CTT GTT CAA ACG CCC GGA ATC ATT-3' and $5^{\prime}$-TGC TTG ACT GCAGGG ACC GAG AGG TTT GGG-3'; Primer 2, 5' -ATC AGT GCAGGG ACC GAG ATG-3' and $5^{\prime}$-AAG CAG CCG ATA AAC ACT CCT T-3') and one control primer (5'-AGG TCG CGA GAT TGG TCG CTA GGT CAT GCA-3' and 5'-AAGACC TCG AGA GAC CCT CTT CAA CAC GT-3'). Embryos displaying only control primer amplification were considered XX.

\section{In vitro culture}

After IVF, presumptive zygotes were partially denuded of cumulus cells by vigorous pipetting and cultured in SOF medium supplemented with $2.5 \% \mathrm{FBS}$ and $5 \mathrm{mg} / \mathrm{ml} \mathrm{BSA}$ at $38.5{ }^{\circ} \mathrm{C}$ in an atmosphere of $5 \% \mathrm{CO}_{2}$ in air under saturated humidity. Groups of 15-20 presumptive zygotes were cultured in $100 \mu \mathrm{l}$ drops. The embryos were washed and transferred to $100 \mu \mathrm{l}$ drops of IVC medium supplemented with $0 \mathrm{nM}$ (control) and $5 \mathrm{nM}$ TSA $70 \mathrm{~h}$ after IVF and remained in TSA-supplemented medium until collection (day 5 embryos or blastocysts).

TSA was diluted at a concentration of $3.3 \mathrm{mM}$ in ethanol and diluted to a final concentration of $5 \mathrm{nM}$ in SOF medium.

\section{Cell cycle evaluation}

Embryos $48 \mathrm{~h}$ after TSA supplementation were collected (118 $\mathrm{h}$ post-IVF). First, hyaluronidase was used to remove any 
remaining cumulus cells. Then, every structure was fixed with $4 \%$ formaldehyde for $20 \mathrm{~min}$ at $37{ }^{\circ} \mathrm{C}$ and stained with Hoechst 33342 for $15 \mathrm{~min}$. The embryos were washed in PBS and examined under a fluorescence microscope. Each structure was classified regarding their cleavage cycle (2nd, 3rd, 4th, and 5th).

\section{Immunocytochemistry of H3K9ac}

After $48 \mathrm{~h}$ of treatment with TSA, embryos (118 $\mathrm{h}$ post-IVF) were fixed in $4 \%$ paraformaldehyde for $30 \mathrm{~min}$ at $37^{\circ} \mathrm{C}$ and stored at $4{ }^{\circ} \mathrm{C}$ in PBS supplemented with $3 \%$ BSA and $0.5 \%$ Triton X-100 for up to 1 week. Blastocysts were fixed by the same procedure 7 days after IVF. The fixed embryos were incubated with blocking solution (3\% BSA and $0.2 \%$ Tween 20 in PBS) for $1 \mathrm{~h}$ at room temperature. Next, embryos were incubated with the primary antibody (mouse anti-H3K9ac MAB, $1: 100)$ for $12 \mathrm{~h}$ at $4{ }^{\circ} \mathrm{C}$. The embryos were then washed three times in PBS for $10 \mathrm{~min}$ and incubated with the secondary antibody (CY3-conjugated sheep anti-mouse antibody, 1:200 for 8-16 cell embryos; and Alexa 488-chicken antimouse, 1:200 for blastocysts (Alexa Fluor, Invitrogen, Carlsbad, (A, USA)) for $2 \mathrm{~h}$. The nuclei were stained with $10 \mu \mathrm{l} / \mathrm{ml}$ Hoechst 33342 for $10 \mathrm{~min}$. The embryos were washed three times for $10 \mathrm{~min}$ in PBS and examined under a fluorescence microscope. Reactions in which the primary antibody was omitted served as negative control. Images of each structure were captured with an AxioCam camera and stored using the AxioVision 4.7.1 Software (Carl Zeiss, Jena, Germany).

Images were measured for fluorescence intensity on each blastomere (day 5 embryos) and on ICM and TE separately (blastocysts) using Adobe Photoshop CS3 (Adobe Systems, Inc.). First, the two images from each embryo (Hoechst and CY3 or Alexa 488) were placed together in a new file, in different layers. For blastocyst images, inner cell mass region was removed and placed in another file, using the elliptical marquee tool. Nuclei were selected with the magic wand tool in Hoechst layer for each blastomere (day 5 embryos) or for all nuclei area (ICM and TE files). Sections were measured using the histogram function through the red or green channel, according to secondary antibody. Background levels were measured for each image and subtracted from nuclei levels. Photoshop assigns intensity values between 0 and 255 to each pixel in the selected area and then averages these intensities, giving the mean intensity of the selected section.

On day 5 embryos, we analyzed each embryo separately. Histogram function for each blastomere was recorded and background level was subtracted. Then, we selected the lower blastomere level for normalization (the normalizing blastomere). For that, each blastomere level was divided by the normalizing blastomere, and as a result, in each embryo values started from 1 onward (homogeneous embryos had levels around 1, and heterogeneous embryos had levels ranging from 1 to 4.5$)$. This procedure was performed to allow comparison between embryos. Then, the degree of reactivity was classified into five categories, regarding the normalized intensity value. Categories 1-2 corresponded to blastomeres displaying low variation (one- to twofold) on $\mathrm{H} 3 \mathrm{k}$ 9ac levels compared with the normalizing blastomere; categories 5 and 6 corresponded to blastomeres displaying high variation (five- to sixfold) on $\mathrm{H} 3 \mathrm{k}$ 9ac levels compared with the normalized blastomere.

\section{Real-time quantitative PCR}

The preamplification of cDNA targets was necessary due to the small amount of mRNA obtained from each embryo. We used for preamplification the system validated by Mengual et al. (2008), and we also performed a separate experiment in our laboratory to compare the correlation of cDNA quantity (Nanodrop; Thermo Scientific, Waltham, MA, USA) and gene expression data $(\Delta C T)$ between non-preamplified and preamplified samples (Saraiva et al. 2012). For real-time quantitative PCR (RT-qPCR), individual day 7 blastocysts were placed in $0.2 \mathrm{ml}$ PCR tubes with $2 \mu \mathrm{l}$ PBS containing RNAse Out (Invitrogen) 4:1, frozen in liquid nitrogen, and stored at $-80^{\circ} \mathrm{C}$. Total RNA was obtained from individual blastocysts with the RNeasy Micro kit (Qiagen). cDNA was synthesized using ImProm-II RT System (Promega) according to the manufacturer's instructions. The cDNA from each embryo was preamplified using TaqMan PreAmp Master Mix (Applied Biosystems) with $45 \mathrm{nM}$ of the following primers: GAPDH (NM_001034034, 76 bp) F: 5'-AAGGCCATCACCATCTTCCA-3', R: 5'-CCACTACATACTCAGCACCAGCAT-3'; XIST (NR_001464, 99 bp) F: 5'-TTGGCTTTTAGATTAATTTGATGAACAGCAT-3', R: 5'-CCCTTTAGACTAGGCCCATTTCATA-3'; and G6PD (XM_583628, 58 bp) F: 5'-GCCGTCCTCTATGTGGAAAATGA-3' ${ }^{\prime}$, R: 5'-CGCAGCGCAGGATGAAG-3'.

Preamplification conditions were $95^{\circ} \mathrm{C} 10 \mathrm{~min}$, followed by 14 cycles of $95^{\circ} \mathrm{C} 15 \mathrm{~s}, 57^{\circ} \mathrm{C}$ for $45 \mathrm{~s}$, and $72{ }^{\circ} \mathrm{C}$ for $4 \mathrm{~min}$. Amplified cDNA was diluted 1:4. GAPDH was used as an internal housekeeping control. RT-qPCR was performed using the Applied Biosystems 7500 Real-Time PCR System (Applied Biosystems). Amplifications were carried out in a final reaction volume of $20 \mu \mathrm{l}$ containing SYBR Green master mix (Applied Biosystems), $2 \mu \mathrm{l}$ cDNA template and 6 pmol primers. PCR conditions were $50{ }^{\circ} \mathrm{C}$ for $2 \mathrm{~min}$ and $95{ }^{\circ} \mathrm{C}$ for $10 \mathrm{~min}$, followed by 40 cycles of $95^{\circ} \mathrm{C}$ for $15 \mathrm{~s}, 60^{\circ} \mathrm{C}$ for $30 \mathrm{~s}$, and $72{ }^{\circ} \mathrm{C}$ for $40 \mathrm{~s}$. The melting curves were acquired after PCR amplification confirming the specificity of the amplified products. Results were analyzed as G6PD and XIST gene expression relative to the housekeeping gene expression using a standard curve (Larionov et al. 2005). Standard curve of each gene (G6PD, $X I S T$, and $G A P D H$ ) was prepared by purifying the product of RT-qPCR reactions using QIAquick PCR Purification Kit (Qiagen). Dilutions ranged from 1 to $1: 10000$, totaling five points.

\section{Statistical analysis}

Differences in fluorescence intensity in blastomeres from control and treated embryos were compared using unpaired t-test. Mean frequency of each category of normalized blastomeres and fluorescence intensity in inner cell mass and TE were analyzed by one-way ANOVA and means were compared by the Tukey's test. Blastocyst rates and distribution of control and TSA-treated embryos in respect to their cellular cycles were analyzed by the $\chi^{2}$ test. Relative expression levels of G6PD and XIST were compared by Mann-Whitney 
nonparametric test. All analysis were carried out using SAS 9.1 Software (SAS Institute, Inc., NC, USA), with a 5\% level of significance.

\section{Declaration of interest}

The authors declare that there is no conflict of interest that could be perceived as prejudicing the impartiality of the research reported.

\section{Funding}

This study was supported by Sao Paulo Research Foundation (FAPESP; grant numbers 2008/58370-0, 2009/54510-4).

\section{References}

Augui S, Nora EP \& Heard E 2011 Regulation of X-chromosome inactivation by the X-inactivation centre. Nature Reviews. Genetics 12 429-442. (doi:10.1038/nrg2987)

Avery B, Jorgensen C, Madison V \& Greve T 1992 Morphological development and sex of bovine in vitro-fertilized embryos. Molecular Reproduction and Development 32 265-270. (doi:10.1002/mrd. 1080320312)

Basrur PK, Farazmand A, Stranzinger G, Graphodatskaya D, Reyes ER \& King WA 2004 Expression pattern of X-linked genes in sex chromosome aneuploid bovine cells. Chromosome Research 12 263-273. (doi:10. 1023/B:CHRO.0000021865.39998.89)

Bermejo-Alvarez P, Rizos D, Lonergan P \& Gutierrez-Adan A 2011 Transcriptional sexual dimorphism in elongating bovine embryos: implications for $\mathrm{XCl}$ and sex determination genes. Reproduction 141 801-808. (doi:10.1530/REP-11-0006)

Chaumeil J, Baccon P, Wutz A \& Heard E 2006 A novel role for Xist RNA in the formation of a repressive nuclear compartment into which genes are recruited when silenced. Genes and Development 20 2223-2237. (doi:10.1101/gad.380906)

De La Fuente R, Hahnel A, Basrur PK \& King WA 1999 X inactive-specific transcript (Xist) expression and $X$ chromosome inactivation in the preattachment bovine embryo. Biology of Reproduction 60 769-775. (doi:10.1095/biolreprod60.3.769)

Edwards J, King W, Kawarsky S \& Ealy A 2001 Responsiveness of early embryos to environmental insults: potential protective roles of hsp70 and glutathione. Theriogenology 55 209-223. (doi:10.1016/S0093-691X(00)00455-6)

Fernandez-Gonzalez R, Moreira P, Bilbao A, Jimenez A, Perez-Crespo M, Ramirez M, De Fonseca F, Pintado B \& Gutierrez-Adan A 2004 Longterm effect of in vitro culture of mouse embryos with serum on mRNA expression of imprinting genes, development, and behavior. PNAS 101 5880-5885. (doi:10.1073/pnas.0308560101)

Gutiérrez-Adán A, Oter M, Martínez-Madrid B, Pintado B \& De La Fuente J 2000 Differential expression of two genes located on the $\mathrm{X}$ chromosome between male and female in vitro-produced bovine embryos at the blastocyst stage. Molecular Reproduction and Development 55 146-151. (doi:10. 1002/(SICl)1098-2795(200002)55:2 < 146::AID-MRD3 > 3.0.CO;2-F)

Hamano K 2002 Sex preselection in bovine by separation of $X$ - and Y-chromosome bearing spermatozoa. Journal of Reproduction and Development 53 27-28. (doi:10.1262/JRD.18141)

Johnstone RW 2002 Histone-deacetylase inhibitors: novel drugs for the treatment of cancer. Nature Reviews. Drug Discovery 1 287-299. (doi:10.1038/nrd772)

Kalantry S, Purushothaman S, Bowen RB, Starmer J \& Magnuson T 2009 Evidence of Xist RNA-independent initiation of mouse imprinted X-chromosome inactivation. Nature 460 647-651. (doi:10.1038/ nature08161)

Koyama Y, Adachi M, Sekiya M, Takekawa M \& Imai K 2000 Histone deacetylase inhibitors suppress IL-2-mediated gene expression prior to induction of apoptosis. Blood 96 1490-1495.
Larionov A, Krause A \& Miller W 2005 A standard curve based method for relative real time PCR data processing. BMC Bioinformatics 662 . (doi:10.1186/1471-2105-6-62)

Lonergan P, Khatir H, Piumi F, Rieger D, Humblot P \& Boland M 1999 Effect of time interval from insemination to first cleavage on the developmental characteristics, sex ratio and pregnancy rate after transfer of bovine embryos. Journal of Reproduction and Fertility 117 159-167. (doi:10. 1530/jrf.0.1170159)

Lopes AS, Wrenzycki C, Ramsing NB, Herrmann D, Niemann H, Løvendahl P, Greve T \& Callesen H 2007 Respiration rates correlate with mRNA expression of G6PD and GLUT1 genes in individual bovine in vitroproduced blastocysts. Theriogenology 68 223-236. (doi:10.1016/j.theriogenology.2007.04.055)

Mak W, Nesterova TB, Napoles M, Appanah R, Yamanaka S, Otte AP \& Brockdorff N 2004 Reactivation of the paternal X chromosome in early mouse embryos. Science 303 666. (doi:10.1126/science.1092674)

Matoba S, Inoue K, Kohda T, Sugimoto M, Mizutani E, Ogonuki N, Nakamura T, Abe K, Nakano T, Ishino F \& Ogura A 2011 RNAi-mediated knockdown of Xist can rescue the impared postimplantation development of cloned mouse embryos. PNAS 108 20621-20626. (doi:10.1073/ pnas.1112664108)

Mengual L, Burset M, Marín-Aquilera M, Ribal MJ \& Alcaraz A 2008 Multiplex preamplification of specific cDNA targets prior to gene expression analysis by Taqman Arrays. BMC Research Notes 5 1-21. (doi:10.1186/1756-0500-1-21)

Merighe G, Biase F, Santos-Biase W, Miranda M, De Bem T, Watanabe Y \& Meirelles F 2009 Gene silencing during development of in vitroproduced female bovine embryos. Genetics and Molecular Research 8 1116-1127. (doi:10.4238/vol8-3gmr638)

Morton KM, Herrmann D, Sieg B, Struckmann C, Maxwell WM, Rath D, Evans G, Lucas-Hahn A, Niemann H \& Wrenzycki C 2007 Altered mRNA expression patterns in bovine blastocysts after fertilisation in vitro using flow-cytometrically sex-sorted sperm. Molecular Reproduction and Development 74 931-940. (doi:10.1002/mrd.20573)

Nino-Soto MI, Basrur PK \& King WA 2007 Impact of in vitro production techniques on the expression of X-linked genes in bovine (Bos taurus) oocytes and pre-attachment embryos. Molecular Reproduction and Development 74 144-153. (doi:10.1002/mrd.20575)

O'Neill LP, Keohane AM, Lavender JS, Mccabe V, Heard E, Avner P, Brockdorff N \& Turner BM 1999 A developmental switch in H4 acetylation upstream of Xist plays a role in X chromosome inactivation. EMBO Journal 18 2897-2907. (doi:10.1093/emboj/18.10.2897)

Okamoto I, Otte AP, Allis CD, Reinberg D \& Heard E 2004 Epigenetic dynamics of imprinted $\mathrm{X}$ inactivation during early mouse development. Science 303 644. (doi:10.1126/science.1092727)

Oliveira CS, Saraiva NZ, De Souza MM, Tetzner TAD, De Lima MR \& Garcia JM 2010 Effects of histone hyperacetylation on the preimplantation development of male and female bovine embryos. Reproduction, Fertility, and Development 22 1041-1048. (doi:10.1071/RD09238)

Oliveira CS, Naiara NZ, De Souza MM, Tetzner TAD, De Lima M \& Garcia JM 2011 Supplementation with the histone deacetylase inhibitor trichostatin A during in vitro culture of bovine embryos. Zygote [in press]. (doi:10.1017/S0967199411000505)

Peippo J, Farazmand A, Kurkilahti M, Markkula M, Basrur PK \& King WA 2002 Sex-chromosome linked gene expression in in-vitro produced bovine embryos. Molecular Human Reproduction 8 923-929. (doi:10. 1093/molehr/8.10.923)

Saraiva NZ, Oliveira CS, Tetzner TAD, Lima MR, Melo DS, Niciura SC \& Garcia JM 2012 Chemically assisted enucleation results in higher G6PD expression in early bovine female embryos obtained by somatic cell nuclear transfer. Cellular Reprogramming 14 425-435. (doi:10.1089/cell.2011.0077)

Seidel GE, Schenk JL, Herickhoff LA, Doyle SP, Brink Z, Green RD \& Cran DG 1999 Insemination of heifers with sexed sperm. Theriogenology 52 1407-1420. (doi:10.1016/S0093-691X(99)00226-5)

Splinter E, Wit E, Nora EP, Klous P \& Werken HJG 2011 The inactive X chromosome adopts a unique three-dimensional conformation that is dependent on Xist RNA. Genes and Development 25 1371-1383. (doi:10.1101/gad.633311)

Williams LH, Kalantry S, Starmer J \& Magnuson T 2011 Transcription precedes loss of Xist coating and depletion of H3K27me3 during $\mathrm{X}$-chromosome reprogramming in the mouse inner cell mass. Development 138 2049-2057. (doi:10.1242/dev.061176) 
Wrenzycki C, Lucas-Hahn A, Herrmann D, Lemme E, Korsawe K \& Niemann H 2002 In vitro production and nuclear transfer affect dosage compensation of the X-linked gene transcripts G6PD, PGK, and Xist in preimplantation bovine embryos. Biology of Reproduction 66 127-134. (doi:10.1095/biolreprod66.1.127)

Xu K, Yadav B, King W \& Betteridge K 1992 Sex-related differences in developmental rates of bovine embryos produced and cultured in vitro. Molecular Reproduction and Development 31 249-252. (doi:10.1002/ mrd.1080310404)
Yakovlev A, Khafizova M, Abdullaev Z, Loukinov D \& Kondratyev A 2010 Epigenetic regulation of caspase-3 gene expression in rat brain development. Gene 450 103-108. (doi:10.1016/j.gene.2009.10.008)

Received 13 September 2012

First decision 12 October 2012

Revised manuscript received 13 October 2012

Accepted 22 October 2012 